\title{
A CANDIDATE GENE ASSOCIATION STUDY OF FKBP5 AND CRHR1 POLYMORPHISMS IN RELATION TO WAR-RELATED POSTTRAUMATIC STRESS DISORDER
}

\author{
Nenad Jaksic ${ }^{1}$, Emina Šabić Džananović ${ }^{2}$, Branka Aukst Margetic ${ }^{3,4}$, Dusko Rudan ${ }^{1}$, Ana Cima Franc ${ }^{1}$, \\ Nada Bozina $^{4,5}$, Elma Ferić Bojić ${ }^{6}$ Sabina Kučukalić ${ }^{2}$, Alma Džubur Kulenović ${ }^{2}$, Damir Marjanovićc \\ Esmina Avdibegović ${ }^{7}$, Dragan Babić ${ }^{8}$, Ferid Agani ${ }^{9}$, Abdulah Kučukalić ${ }^{2}$, Alma Bravo Mehmedbašić2, \\ Nermina Kravic ${ }^{7}$, Mirnesa Muminović Umihanic ${ }^{10}$, Osman Sinanović ${ }^{11}$, Romana Babic ${ }^{8}$, \\ Marko Pavlovici $^{8}$, Shpend Haxhibeqiri ${ }^{12}$, Aferdita Goci Uka ${ }^{12}$, Blerina Hoxha ${ }^{12}$, \\ Valdete Haxhibeqiri $^{12}$, Christiane Ziegler ${ }^{13}$, Christiane Wolf ${ }^{14}$, Bodo Warrings ${ }^{14}$, \\ Katharina Domschke ${ }^{13}$, Jürgen Deckert ${ }^{14}$ \& Miro Jakovljevic ${ }^{1,4}$ \\ ${ }^{I}$ Department of Psychiatry, University Hospital Center Zagreb, Zagreb, Croatia \\ ${ }^{2}$ Department of Psychiatry, University Clinical Center, Sarajevo, Bosnia and Herzegovina \\ ${ }^{3}$ Department of Psychiatry, University Hospital Center Sestre Milosrdnice, Zagreb, Croatia \\ ${ }^{4}$ School of Medicine, University of Zagreb, Zagreb, Croatia \\ ${ }^{5}$ Department of Laboratory Diagnostics, University Hospital Center Zagreb, Zagreb, Croatia \\ ${ }^{6}$ Department of Genetics and Bioengineering, International Burch University, Sarajevo, Bosnia and Herzegovina \\ ${ }^{7}$ Department of Psychiatry, University Clinical Center of Tuzla, Tuzla, Bosnia and Herzegovina \\ ${ }^{8}$ Department of Psychiatry, University Clinical Center of Mostar, Mostar, Bosnia and Herzegovina \\ ${ }^{9}$ Faculty of Medicine, University Hasan Prishtina, Prishtina, Kosovo \\ ${ }^{10}$ Community Health Center Zivinice, Zivinice, Bosnia and Herzegovina \\ ${ }^{11}$ Department of Neurology, University Clinical Center of Tuzla, Tuzla, Bosnia and Herzegovina \\ ${ }^{12}$ Department of Psychiatry, University Clinical Center of Kosovo, Prishtina, Kosovo \\ ${ }^{13}$ Department of Psychiatry and Psychotherapy, Medical Center - University of Freiburg, \\ Faculty of Medicine, University of Freiburg, Germany \\ ${ }^{14}$ Department of Psychiatry, Psychosomatics and Psychotherapy, University Hospital Würzburg, Würzburg, Germany
}

received: 25.1.2019;

revised: 25.4.2019;

accepted: 16.5 .2019

\section{SUMMARY}

Background: Posttraumatic stress disorder (PTSD) is a highly frequent and disabling psychiatric condition among war-affected populations. The FK506-binding protein 5 (FKBP5) gene and the corticotropin-releasing hormone receptor 1 (CRHR1) gene have previously been implicated in an elevated risk of peritraumatic dissociation and PTSD development. Our aim was to investigate the association between FKBP5 and CRHR1 genotypes and PTSD diagnosis and severity among individuals who were affected by the Balkan wars during the 1990s.

Subjects and methods: This study included participants with current PTSD, remitted PTSD and healthy volunteers $(N=719,487$ males), who were recruited between 2013 and 2015 within the framework of the South Eastern Europe (SEE) - PTSD Study. Psychometric methods comprised the Mini International Neuropsychiatric Interview (M.I.N.I.), the Clinician Administrated PTSD Scale (CAPS), and the Brief Symptom Inventory (BSI). FKBP5 rs 1360780 and CRHR1 rs17689918 genotypes were determined using a KASP genotyping assay.

Results: Tests for deviation from Hardy Weinberg equilibrium showed no significant results. Logistic and linear regression was used to examine the associations between the FKBP5 SNP rs 1360780 and the CRHR1 SNP rs17689918 with PTSD diagnosis and severity, as well as general psychiatric symptom severity, separately for current and remitted PTSD patients. There were nominally significant associations under a dominant model between the rs1360780 C allele and PTSD diagnosis as well as symptom severity, which however, were not significant anymore after Bonferroni adjustment ( $\alpha=0.002)$. For CRHR1 rs17689918 no significant associations were detected.

Conclusion: We found nominally, but not Bonferroni corrected significant associations between the FKBP5 polymorphism rs1360780 and PTSD susceptibility among individuals affected by the Balkan wars. For elucidating this gene's real resilience/vulnerability potential, environmental influences should be taken into account.

Key words: PTSD - FKBP5 - CRHR1 - trauma - war

\section{INTRODUCTION}

Posttraumatic stress disorder (PTSD) is a highly frequent and disabling psychiatric condition among waraffected populations (Gates et al. 2012, Wisco et al.
2014, Sagud et al. 2017). Various individual predispositions, including genetic susceptibility, related to the pathophysiology of PTSD can increase the chances of its development and reoccurrence (Domschke 2012, Jakovljevic et al. 2012a). 
Anxious disorders are significantly correlated with levels of stressful experiences. Prior research has shown that these disorders are characterised by dysfunction of mineralocorticoid (MR) and glucocorticoid receptors (GR), which are the main effector receptors of the hypothalamic-pituitary-adrenal (HPA) axis. Corticotropin-releasing hormone receptor 1 (CRHR1) is one of the mediators of the HPA axis as the binding of corticotropin-releasing hormone $(\mathrm{CRH})$ to this receptor subsequently leads to the release of cortisol (Holsboer \& Ising 2008, Refojo \& Holsboer 2009). The CRHRl gene has been subject to various studies implicating its potential role as a candidate gene for mood and anxiety disorders and several of its polymorphisms have been investigated concerning their influence on PTSD risk (Amstadter et al. 2011, White et al. 2013). The minor allele of the CRHR1 SNP rs17689918 increases the risk for developing panic disorder (PD) in females and is suggested to result a reduced flight behaviour, predominant generalization of fear, increasd anxious apprehension and anxiety sensitivity via a reduced gene expression of CRHRl (Weber et al. 2016).

On the other hand, the functions of MR and GR are regulated by several chaperone proteins. The genetic variation within one of these proteins, the FK506 Binding Protein 5 (FKBP5) which regulates the sensitivity of the glucocorticoid receptors, is considered to be one of the main risk factors for the development of stress-related disorders, including PTSD (Zannas et al. 2016). By investigating the influence of the FKBP5 polymorphism rs1360780 on the corticosteroid receptor, which mediates the regulation of the HPA gland, researchers have concluded that individuals homozygous for the minor allele manifest incomplete normalisation of the cortisol secretion, caused by stress (Ising et al. 2008). Homozygous carriers of the rs 1360780 minor alleles manifested insufficient recovery of cortisol associated with increased levels of anxiety after being exposed to psycho-social stress. This suggests that individuals who carry the risk variants of these polymorphisms are at risk of chronic manifestations of higher cortisol levels when exposed to repeated stress (Ising et al. 2008).

While the research mentioned above has dealt with the recovery from psycho-social stress by investigating FKBP5 polymorphisms of healthy controls, some of the more recent research explored the relation between FKBP5 polymorphisms and lifetime PTSD symptoms. The dysfunction of the HPA axis is also featured in PTSD (Sherin \& Nemeroff 2011). It is exactly those genes involved in the HPA axis functioning, that are considered to be especially apt for investigating the interactions between genes and environment, which are highly present in the development of PTSD and its symptoms. Genes that regulate the activity of the GR, such as co-chaperone FK506, by linking the protein 5 (FKBP5) to it, have been described to influence the impact of childhood trauma due to alterations within the
HPA axis (Watkins et al. 2016). Single nucleotide polymorphisms (SNPs) in the FKBP5 gene are linked to higher FKBP5 protein expression, which leads to GR resistance and a dysfunction of the negative return connection (Binder 2009). SPNs might, therefore, be associated with a slower return to the baseline stressinduced levels of cortisol, which can potentially increase the risk of PTSD development (Binder 2009). Specific SPNs (e.g., rs3800373 and rs1360780) in FKBP5 are thus conceptualized as risk factors for PTDS development (Watkins et al. 2016). Besides, specific FKBP5 polymorphisms were also found to be associated with peritraumatic dissociation (Koenen et al. 2005), a strong risk factor for subsequent PTSD development, as well as with effectiveness of psychotherapy for PTSD (Wilker et al. 2014).

So far, prior research has been performed in AfricanAmerican (Binder et al. 2008), South Asian (Kohrt et al. 2015) and mixed Caucasian/African-American populations (Watkins et al. 2016, Young et al. 2018). Studies conducted in European populations, particularly among war-affected individuals, are very scarce. Our aim was to examine the association of the FKBP5 SNP rs1360780 and CRHR1 SNP rs17689918 with PTSD in persons who were involved in the Balkan wars during the 1990 s. It seems these populations have suffered numerous stressful and traumatic experiences, and the prevalence of mental disorders, especially PTSD, is particularly high (Bogic et al. 2012). As specific genes can promote the occurence of certain psychiatric disorders, including war-related PTSD, the findings of this study may further extend our understanding of the complex pathophysiology of PTSD in the framework of the stress-diathesis or vulnerability-resilience model (Jakovljevic et al. 2012a, 2017).

\section{SUBJECTS AND METHODS}

\section{Subjects}

In total 719 (mean age $49.4 \pm 7.9 ; 487$ males) participants including 218 patients with current PTSD (mean age 50.1 $\pm 6.7 ; 157$ males), 151 remitted PTSD subjects (mean age $49.5 \pm 8.2$; 98 males) and 350 healthy volunteers (mean age $48.8 \pm 8.5 ; 232$ males), were recruited between 2013 and 2015 within the framework of the South Eastern Europe (SEE) - PTSD Study (Dzubur Kulenovic et al. 2016). The research was carried out at five centres in Bosnia-Herzegovina (Sarajevo, Mostar, Tuzla), Croatia (Zagreb), and the Republic of Kosovo (Pristina). These are all countries whose population has experienced severe war-related trauma between 1991 and 1999.

The general inclusion criteria were: DSM-IV current or life-time PTSD or no PTSD, participants must be at least 16 years at the time of traumatization and currently not older than 65 years. The exclusion criteria were: the presence of organic depression, epilepsy, psychotic symptoms, addiction (except smoking), intellectual 
disability, oncological disorders, valproid acid use and $1^{\text {st }}$ and $2^{\text {nd }}$ degree relation to an already recruited person. More detailed information regarding recruitment, diagnostic assessment, inclusion and exclusion criteria, as well as sample size and gender distribution are described in detail elsewhere (Dzubur-Kulenovic et al. 2016).

Ethical votes at the participating clinical centers were obtained between 2011 and 2013 on the basis of local translations of an information and consent form designed by the Sarajevo center. Participants thus were informed and gave written informed consent according to the principles of the declaration of Helsinki (WMA 2013).

\section{Psychometric Instruments}

The presence or absence of PTSD symptoms in the screening stage was assessed using a structured clinical interview - Mini International Neuropsychiatric Interview (M.I.N.I.). The Clinician Administrated PTSD Scale (CAPS) (Blake et al. 1996) was performed to make a categorical PTSD diagnosis (current or remitted PTSD) and to assess the severity of PTSD symptoms. Interviews were performed by trained medical personnel (psychiatrists, clinical psychologists or psychiatric residents). For the assessment of general psychiatric symptoms we used a self-report measure - the Brief Symptom Inventory (BSI) (Derogatis \& Melisaratos 1983). The internal reliability of the BSI for the entire sample was high (Cronbach $\alpha=0.987)$.

\section{Molecular Analyses}

For genotyping, genomic DNA was isolated from frozen venous blood by using the FlexiGene DNA Kit (Qiagen, Hilden, Germany) according to manufacturer's instructions and stored at the Laboratory of the Department of Psychiatry, Psychosomatics and Psychotherapy, University of Würzburg, Germany at $-80^{\circ} \mathrm{C}$.

FKBP5 rs1360780 genotypes were determined using a custom designed KASP genotyping assay (LGC, Berlin, Germany). PCR reaction including an end-point fluorescent read-out was performed according to manufacturers' instructions in a CFX384 Touch Cycler (Biorad, Munich, Germany). Genotype analysis was performed using the CFX Manager Software.

CRHR1 rs17689918 genotyping was conducted via PCR-RFLP as follows: DNA was amplified by PCR $(25 \mu \mathrm{l}$ reaction mix: $50 \mathrm{ng}$ genomic DNA, $0.4 \mathrm{mM}$ of each primer, 0.1 of each $\mathrm{mM}$ nucleotide, $1 \mathrm{mM} \mathrm{MgCL} 2,20 \mathrm{mM}$ $\left(\mathrm{NH}_{4}\right)_{2} \mathrm{SO}_{4}, 75 \mathrm{mM}$ Tris- $\mathrm{HCl}$ (pH9), 0.01\% Tween 20 and $0.3 \mathrm{U} \mathrm{Taq}^{\mathrm{TM}}$ DNA plymerase) using the oligonucleotide primers F: 5'-CACTCGGGAAAATGCAAAGCA-3' and R: 5'-TGCAAAGTTGGAAGCAAGCAC-3' and the following cycler conditions: 3 min denaturation at $95^{\circ} \mathrm{C}, 35$ cycles each $45 \mathrm{~s}$ at $95^{\circ} \mathrm{C}, 45 \mathrm{~s}$ at $60.5^{\circ} \mathrm{C}$ and $45 \mathrm{~s}$ at $72^{\circ} \mathrm{C}$ and a final extension step of $5 \mathrm{~min}$ at $72^{\circ} \mathrm{C}$. PCR fragments were digested with the restriction endonuclease HpyCH4V (NEB, Frankfurt a. Main, Germany) for $3 \mathrm{~h}$ at $37^{\circ} \mathrm{C}$, which results in differentially sized fragments representing the respective genotypes. The fragments were separated on a $4 \%$ agarose gel by electrophoresis and visualized with ethidium bromide. Fragment lengths and resulting genotypes were determined by two independent investigators blinded for diagnosis.

\section{Statistical Analysis}

Statistics were performed using PLINK 1.9. With a minor allele frequency (MAF) higher than $10 \%$ both variants were polymorphous, reached a call rate of $98 \%$ and controls did not deviate from Hardy Weinberg equilibrium $(\mathrm{P} \geq 0.01)$. Logistic regression was used for case-control analyses and linear regression were carried out for CAPS and BSI analyses, separately for the current and remitted PTSD patients. The following models were tested in all phenotypes: additive allelic, dominant (based on the minor allele), as well as the genotypic model. The significance level was Bonferroni adjusted for 23 variants that were analyzed in total in the entire project $(\alpha=0.002)$.

\section{RESULTS}

In order to characterize the role of FKBP5 and CRHR1 on PTSD, two well investigated SNPs rs 1360780 and rs17689918 were subjected to a case-control analysis in altogether 719 participants. The influence of genotypes on the dimensional CAPS and BSI questionnaires, both linked to PTSD, was determined in all cases with current PTSD symptoms and additionally in those with diagnosed lifetime PTSD.

\section{FK506-binding protein 5}

Three case-control analyses for FKBP5 rs1360780 were carried out to test the allelic, dominant, and genotypic models, respectively. The logistic regression analysis identified a nominally significant association for the dominant model ( $\mathrm{P}=0.0423$; Table 1$)$, suggesting that individuals who are homozygous for the $\mathrm{C}$ allele are at a higher risk for developing PTSD. However, following the Bonferroni adjustment for multiple testing, this result became insignificant. Results for the genotypic model $(\mathrm{P}=0.0819$; Table 1$)$ was not even nominally significant and showed for the allelic model no significance at all $(\mathrm{P}>0.1)$. Detailed allele and genotype distributions for cases and controls are given in Table 1.

Linear regression analyses were performed with genotypes predicting the total CAPS and BSI scores, in additive allelic, dominant and genotypic models for current and remitted PTSD separately. The results of the regression analyses for the CAPS total scores reached in none of the calculated models any significance, neither in the current nor in the remitted PTSD group ( $\mathrm{p}_{\text {all }}>0.05$; Table 1). Only the allelic model predicting BSI total score, not in the current $(\mathrm{p}>0.1)$, but in the remitted PTSD group was nominally significant $(\mathrm{P}=0.0493)$, 
Table 1. Association results of FKBP5 rs1360780, along with genotype- and allele counts, for individuals in analysis, CAPS and BSI means and standard deviations (SD), as well as nominal p-values

\begin{tabular}{|c|c|c|c|c|c|c|c|}
\hline \multirow{2}{*}{ FKBP5 rs1360780 } & \multicolumn{2}{|c|}{ Allelic Model } & \multicolumn{3}{|c|}{ Genotypic Model } & \multicolumn{2}{|c|}{ Dominant Model } \\
\hline & $\mathrm{T}$ & $\mathrm{C}$ & TT & $\mathrm{TC}$ & $\mathrm{CC}$ & $\mathrm{TT} / \mathrm{TC}$ & $\mathrm{CC}$ \\
\hline Controls & 209 & 479 & 27 & 155 & 162 & 182 & 162 \\
\hline PTSD $_{\text {lifetime }}$ & 79 & 217 & 12 & 55 & 81 & 67 & 81 \\
\hline PTSD $_{\text {current }}$ & 112 & 304 & 18 & 76 & 114 & 94 & 114 \\
\hline $\mathrm{P}_{\text {case-control-value }}$ & \multicolumn{2}{|c|}{0.1417} & \multicolumn{3}{|c|}{0.0819} & \multicolumn{2}{|c|}{0.0423} \\
\hline $\operatorname{CAPS}_{\text {lifetime }}($ mean $\pm \mathrm{SD})$ & $67.6 \pm 18.4$ & $66.9 \pm 17.2$ & $67.9 \pm 24.3$ & $67.5 \pm 15.4$ & $67.0 \pm 17.7$ & $67.6 \pm 17.2$ & $67.0 \pm 17.7$ \\
\hline $\mathrm{P}_{\text {CAPS}}$-value & \multicolumn{2}{|c|}{0.8362} & \multicolumn{3}{|c|}{0.9788} & \multicolumn{2}{|c|}{0.844} \\
\hline $\mathrm{CAPS}_{\text {current }}($ mean $\pm \mathrm{SD})$ & $81.9 \pm 21.5$ & $78.2 \pm 20.6$ & $84.7 \pm 20.9$ & $80.7 \pm 21.7$ & $77.1 \pm 20.3$ & $81.5 \pm 21.6$ & $77.1 \pm 20.3$ \\
\hline $\mathrm{P}_{\mathrm{CAPS}}$-value & \multicolumn{2}{|c|}{0.0999} & \multicolumn{3}{|c|}{0.2566} & \multicolumn{2}{|c|}{0.1384} \\
\hline $\mathrm{BSI}_{\text {lifetime }}($ mean $\pm \mathrm{SD})$ & $64.7 \pm 43.8$ & $76.7 \pm 50.6$ & $51.9 \pm 35.4$ & $70.0 \pm 45.8$ & $79.3 \pm 51.7$ & $66.9 \pm 44.7$ & $79.3 \pm 51.7$ \\
\hline $\mathrm{P}_{\mathrm{BSI}^{-} \text {-value }}$ & \multicolumn{2}{|c|}{0.0493} & \multicolumn{3}{|c|}{0.1268} & \multicolumn{2}{|c|}{0.1086} \\
\hline $\mathrm{BSI}_{\text {current }}($ mean $\pm \mathrm{SD})$ & $115.1 \pm 42.4$ & $112.0 \pm 47.9$ & $101.6 \pm 38.6$ & $120.8 \pm 42.7$ & $108.9 \pm 49.7$ & $117.0 \pm 42.6$ & $108.9 \pm 49.7$ \\
\hline $\mathrm{P}_{\mathrm{BSI}^{-} \text {-value }}$ & \multicolumn{2}{|c|}{0.6399} & \multicolumn{3}{|c|}{0.1408} & \multicolumn{2}{|c|}{0.2265} \\
\hline
\end{tabular}

FKBP5 - Dopamine receptor 2; PTSD - posttraumatic stress disorder; CAPS - Clinician Administered PTSD Scale; BSI - Brief Symptom Inventory; Italics indicates $p \leq 0.05$

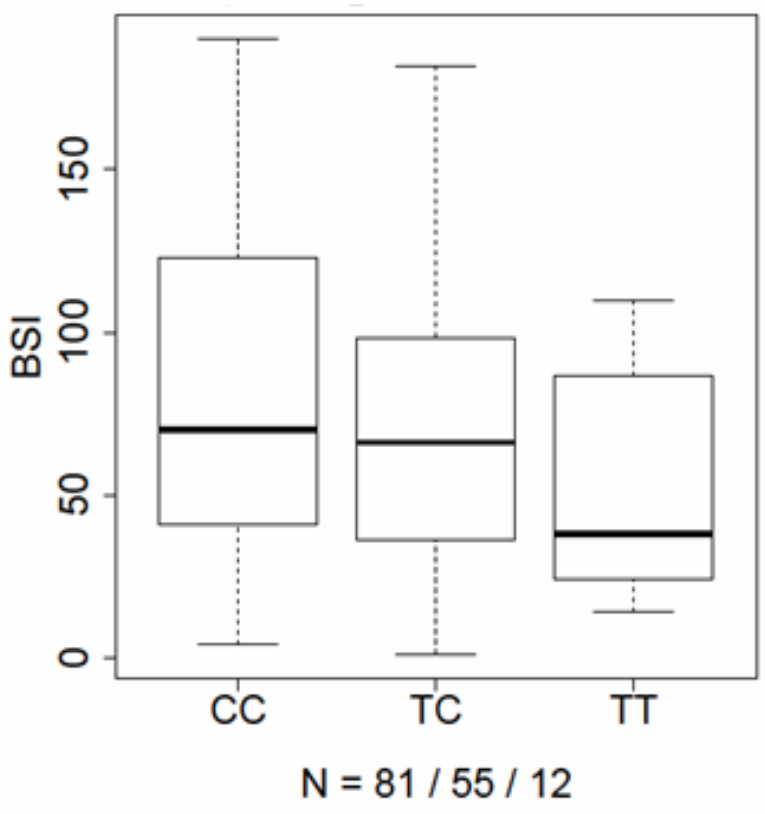

Figure 1. The distribution of the Brief Symptom Inventory (BSI) total values according to FKBP5 genotypes in the additive allelic model within the remitted PTSD group $(\mathrm{n}=148 ; \mathrm{P}=0.0493)$

suggesting an association between the major $\mathrm{C}$ allele and higher BSI scores (Table 1, Figure 1). However, it became insignificant after Bonferroni adjustment. The results of the regression analyses for the CAPS total scores were not even nominally significant in both groups of subjects $(\mathrm{p}>0.09)$.

\section{Corticotropin Releasing Hormone Receptor 1}

No significant associations were identified within the additive allelic, genotypic, and dominant models for rs 17689918, neither for dimensional nor categorical phenotypes $\left(\mathrm{P}_{\mathrm{all}}>0.1\right)$.

\section{DISCUSSION}

This is the first study to assess the association of the FKBP5 polymorphism rs1360780 with PTSD in a European population of war-affected individuals. We recruited participants who were exposed to war activities in the states of former Yugoslavia, with a prevalence of PTSD around $18 \%$ in Croatia and Kosovo and up to $35.5 \%$ in Bosnia and Herzegovina (Priebe et al. 2010). The collapse of Yugoslavia precipitated the worst armed conflict in Europe since 1945, with war activities on the region of former Yugoslavia occuring between 1991 and 2001. Sociopolitical factors influence the frequency of stressful and traumatic exposures and their chronicity and vary significantly in the postwar period.

Contrary to some of the previous studies (e.g., Koenen et al. 2005, Binder et al. 2008, Watkins et al. 2016, Young et al. 2018), the FKBP5 polymorphism rs 1360780 was not associated with PTSD and general psychiatric symptoms in the population of European war-affected persons. It seems the assumed FKBP5 risk alleles described in previous studies do not always implicate higher risk (Zannas et al. 2016). For example, the $\mathrm{G}$ allele of rs4606 within the regulator of $G$ protein signaling 2 gene, although not examined in the current study, has been associated with posttraumatic growth following exposure to the Hurricane Katrina (Dunn et al. 2014). FKBP5 rs1360780 was also linked to less intense depressive symptoms in the context of early institutionalization but low current stress (VanZomeren-Dohm et al. 2015), and to less lifetime PTSD in the absence of child abuse in a highly traumatized cohort (Klengel et al. 2013). In addition, the $\mathrm{C}$ allele was previously described as protective, but in the study of Van Zoren-Dohm et al. (2015), boys with the CC genotype had higher rates of depressive 
symptoms compared to girls with the CC genotype in the context of elevated victimization. These results are actually in line with our nominally significant finding of an association of PTSD with higher BSI scores in remitted patients carrying the $\mathrm{C}$ allele.

Additionally, our results were not able to support previous findings (Amstadter et al. 2011, White et al. 2013) suggesting CRHRl as a mediator of PTSD risk. This may be due to the use of a study population comprising a different genetical background than the ones analysed in earlier research.

This study had several limitations that need to be mentioned. The patient cohort is fairly small, in particular when it is separated into remitted/lifetime PTSD and current PTSD which may have reduced statistical power. Studies in consortia such as the PGC consortia are therefore necessary. Also, trauma type is significantly different among individuals in this study, as the characteristics of the war situation varied between the countries and regions. This may have affected epigenetic processes which possibly confounded the genetic analyses. Another issue is the comorbidity with neuropsychiatric disorders which does not allow for conclusions regarding the specificity of the present findings to PTSD.

We thus may presume that factors related to genetic and cultural background may explain why FKBP5 alleles predicted PTSD symptoms in an urban African American cohort (Binder et al. 2008) or a mixed cohort (Watkins et al. 2016), but not in a rural South Asian cohort (Kohrt et al. 2015) or individuals from Balkan region states in the current study. In addition, numerous other factors, such as post-deployment social support, unemployment and stressful life events are known to predict PTSD in war-affected populations (Jakovljevic et al. 2012a,b, Possemato et al. 2014). Findings of studies linking candidate vulnerability genes (or 'risk alleles') directly to specific psychopathological conditions have proven difficult to replicate. Candidate genes are usually chosen as a target of research based on previous kowledge of biological functional impact of the genes on the symptom that is researched. As previously discussed, these heterogeneous outcomes raise the possibility that what such alleles may confer is increased plasticity, with opposite outcomes being then possible depending on the presence of positive or negative environmental influences (Belsky \& Hartman 2014, Belsky et al. 2009). Yet the exact role of timing, type and duration of these genotype-dependent environmental challenges and the molecular and cellular mechanisms underlying such differential outcomes remain to be elucidated by future studies. Indeed, a recent systematic review has documented a significant influence of the FKBP5 $\mathrm{T}$ allele (SNP rs1360780) on the development of PTSD in adulthood, but only for individuals who were exposed to early-life trauma (Wang et al. 2018).

\section{CONCLUSION}

In contrast to the findings of some previous studies, we only found a nominally significant association of FKBP5 rs1360780 and no association of CRHR1 rs17689918 with PTSD susceptibility among individuals affected by the Balkan wars during the 1990s. The nominally significant finding did not withstand correction for multiple testing. For elucidating these genes' real resilience/vulnerability potential, interaction with other environmental influences should be taken into account in future studies.

\section{Acknowledgements:}

We thank all the participants and their families without whose idealistic and enthusiastic support the study would not have been possible. We also would like to thank at Sarajevo: the Association of Women Victims of War and Bakira Hasecic, the Association of Physically Handicapped, Zilko Buljugija, Zoran Budimlija, MD, PhD, Jasminka Krehic, MD, PhD, Elvira Sabanovic, RSN and Subhija Gusic; in Kosovo: Feride Rushiti, MD, Selvije Izeti, MSc, Vjosa Devaja, MD, Melita Kallaba, MD from Kosova Rehabilitation Center for Trauma Survivors- KRCT; Emirjeta Kumnova, Veprore Shehu from Medica Kosova; Zahrije Podrimqaku Subashi from the Association of Political Prisoners, Kadire Tahiraj from the Center for Promotion of Women's Rights; Arbërore Ulaj, MD, Teuta Haxhiu, MD and Drita Gashi, MD, for their assistance in recruiting and interviewing participants; at Zagreb: Mirica Mavracic, Zoran Bradas, Zrinka Mirkovic and Maja Mezak Herceg for technical assistance in drawing blood and extracting DNA; at Tuzla: the staff of the Department of Transfusion of University Clinical Center of Tuzla, and the staff of the Department of Psychiatry, in particular Emina Hujdur, Medin Omerašević and Avdo Šakušić, MD for technical support and Maja Brkić and Sandra Zornić for their assistance in data collection; at Würzburg: Carola Gagel for technical assistance with extracting DNA. Thanks are highly deserved by and gratefully extended to Peter Riederer as spiritus rector who brought the consortium together. The study was funded by the DAAD program Stability Pact for South Eastern Europe and supported by the DFG-funded RTG 1253 (speaker Pauli) as well as the DFG-funded CRC-TRR58 (projects C02 Domschke, Deckert, and Z02 Deckert, Domschke).

Conflict of interest: None to declare.

\section{Contribution of individual authors:}

Each author has actively participated in the international research project (see Acknowledgments) and, therefore, has substantially contributed to the development and publication of this manuscript.

\section{References}

1. Amstadter AB, Nugent NR, Yang BZ, Miller A, Siburian R, Moorjani $P$ et al: Corticotrophin-releasing hormone type 1 receptor gene (CRHR1) variants predict posttraumatic stress disorder onset and course in pediatric injury patients. Dis Markers 2011; 30:89-99

2. Belsky J, Hartman S: Gene-environment interaction in evolutionary perspective: differential susceptibility to environmental influences. World Psychiatry 2014; 13:87-89 
3. Belsky J, Jonassaint C, Pluess C, Stanton M, Brummett $B$, Williams R: Vulnerability genes or plasticity genes? Mol Psychiatry 2009; 14:746-754

4. Binder EB: The role of FKBP5, a co-chaperone of the glucocorticoid receptorin the pathogenesis and therapy of affective and anxiety disorders. Psychoneuroendocrinology 2009; 34:186-195

5. Binder EB, Bradley RG, Liu W, Epstein MP, Deveau TC, Mercer KB, et al: Association of FKBP5 polymorphisms and childhood abuse with risk of posttraumatic stress disorder symptoms in adults. JAMA 2008; 299:12911305

6. Blake DD, Weathers FW, Nagy LM, Kaloupek DG, Gusman FD, Charney DS, Keane TM: The development of a clinician-administered PTSD scale. J Trauma Stress 1995; 8:75-90

7. Bogic M, Ajdukovic D, Bremner S, Franciskovic T, Galeazzi GM, Kucukalic A, et al: Factors associated with mental disorders in long-settled war refugees: refugees from the former Yugoslavia in Germany, Italy and the UK. Br J Psychiatry 2012; 200:216-23

8. Derogatis L, Melisaratos N: The Brief Symptom Inventory: A introductory report. Psychological Medicine 1983; 13:595-605

9. Domschke K: Patho-genetics of posttraumatic stress disorder. Psychiatr Danub 2012; 3:267-273

10. Dunn EC, Solovieff N, Lowe SR, Gallagher PJ, Chaponis $J$, Rosand $J$, et al: Interaction between genetic variants and exposure to Hurricane Katrina on post-traumatic stress and post-traumatic growth: a prospective analysis of low income adults. J Affect Disord 2014; 152154:243-9

11. Gates MA, Holowka DW, Vasterling JJ, Keane TM, Marx BP, Rosen RC: Posttraumatic stress disorder in veterans and military personnel: epidemiology, screening, and case recognition. Psychol Serv 2012; 9:361-82

12. Holsboer F, Ising M: Central CRH system in depression and anxiety--evidence from clinical studies with $\mathrm{CRH1}$ receptor antagonists. Eur J Pharmacol 2008; 583:350357

13. Ising M, Depping AM, Siebertz A, Lucae S, Unschuld $P G$, Kloiber S, et al: Polymorphisms in the FKBP5 gene region modulate recovery from psychosocial stress in healthy controls. Eur J Neurosci 2008; 28:389-98

14. Jakovljevic M, Brajkovic L, Jaksic N, Loncar M, AukstMargetic B, Lasic D: Posttraumatic stress disorders (PTSD) from different perspectives: a transdisciplinary integrative approach. Psychiatr Danub 2012a; 24:24655

15. Jakovljevic $M$, Brajkovic L, Loncar M, Cima A: Posttraumatic stress disorders (PTSD) between fallacy and facts: what we know and what we don't know? Psychiatr Danub 2012b; 24:241-5

16. Jakovljevic M: Resilience, psychiatry and religion from public and global mental health perspective: Dialogue and Cooperation in the Search for Humanistic Self, Compassionate Society and Empathic Civilization. Psychiatr Danub 2017; 29:238-244

17. Klengel $T$, Mehta D, Anacker $C$, Rex-Haffner $M$, Pruessner JC, Pariante CM, et al: Allele-specific FKBP5 $D N A$ demethylation mediates gene-childhood trauma interactions. Nat Neurosci 2013; 16:33-41
18. Koenen KC, Saxe G, Purcell S, Smoller JW, Bar D, Miller A, et al: Polymorphisms in FKBP5 are associated with peritraumatic dissociation in medically injured children. Mol Psychiatry 2005; 10:1058-1059

19. Kohrt BA, Worthman CM, Ressler KJ, Mercer KB, Upadhaya $N$ et al: Cross-cultural gene- environment interactions in depression, post-traumatic stress disorder, and the cortisol awakening response: FKBP5 polymorphisms and childhood trauma in South Asia. International Review of Psychiatry 2015; 27:180-196

20. Kulenovic AD, Agani F, Avdibegovic E, Jakovljevic M, Babic D, Kucukalic A et al: Molecular Mechanisms of Posttraumatic Stress Disorder (PTSD) as a Basis for Individualized and Personalized Therapy: Rationale, Design and Methods of the South Eastern Europe (SEE)PTSD study. Psychiatr Danub 2016; 28:154-163

21. Possemato K, McKenzie S, McDevitt-Murphy ME, Williams J, Ouimette P: The Relationship Between PostDeployment Factors and PTSD Severity in Recent Combat Veterans. Military Psychology 2014; 26:15-22

22. Priebe $S$, Bogic $M$, Ajdukovic D, Franciskovic $T$, Galeazzi GM, Kucukalic A, et al: Mental disorders following war in the Balkans: a study in 5 countries. Arch Gen Psychiatry 2010; 67:518-28

23. Refojo D, Holsboer F: CRH signaling. Molecular specificity for drug targeting in the CNS. Ann NY Acad Sci 2009; 1179:106-119

24. Sagud M, Jaksic N, Vuksan Cusa B, Loncar M, Loncar I, Mihaljevic Peles A, Milicic D, Jakovljevic M: Cardiovascular disease risk factors in patients with posttraumatic stress disorder (PTSD): A narrative review. Psychiatr Danub 2017; 29:421-30

25. Sherin JE, Nemeroff CB: Post-traumatic stress disorder: the neurobiological impact of psychological trauma. Dialogues Clin Neurosci 2011; 13:263-278

26. VanZomeren-Dohm AA, Pitula CE, Koss KJ, Thomas K, Gunnar MR: FKBP5 Moderation of Depressive Symptoms in Peer Victimized, Post-Institutionalized Children. Psychoneuroendocrinology 2015; 0:426-430

27. Wang $Q$, Shelton $R C$, Dwivedi $Y$ : Interaction between early-life stress and FKBP5 gene variants in major depressive disorder and post-traumatic stress disorder: A systematic review and meta-analysis. J Affect Disord 2018; 225:422-428

28. Watkins LE, Hanc S, Harpaz-Rotema I, Motad NP, Southwicka SM, Krystala JH, et al: FKBP5 polymorphisms, childhood abuse, and PTSD symptoms: Results from the National Health and Resilience in Veterans Study. Psychoneuroendocrinology 2016; 69:98-105

29. Weber H, Richter J, Straube B, et al: Allelic variation in CRHR1 predisposes to panic disorder: evidence for biased fear processing. Mol Psychiatry 2016; 21:813-22

30. White S, Acierno R, Ruggiero KJ, Koenen KC, Kilpatrick $D G$, Galea $S$ et al: Association of CRHR1 variants and posttraumatic stress symptoms in hurricane exposed adults. J Anxiety Disord 2013; 27:678-683

31. Wilker S, Pfeiffer A, Kolassa S, Elbert T, Lingenfelder B, Ovuga E, et al: The role of FKBP5 genotype in moderating long-term effectiveness of exposure-based psychotherapy for posttraumatic stress disorder. Transl Psychiatry 2014; 4:e403 
32. Wisco BE, Marx BP, Wolf EJ, Miller MW, Southwick SM, Pietrzak RH: Posttraumatic stress disorder in the US veteran population: results from the National Health and Resilience in Veterans Study. J Clin Psychiatry 2014; 75:1338-1346

33. Young DA, Inslicht SS, Metzler TJ, Neylan TC, Ross JA: The effects of early trauma and the FKBP5 gene on
PTSD and the HPA axis in a clinical sample of Gulf War veterans. Psychiatry Res 2018; pii:S0165-1781(17)32068-1

34. Zannas AS, Wiechmann T, Gassen NC, Bionder EB: Gene-Stress-Epigenetic Regulation of FKBP5: Clinical and Translational Implications. Neuropsychopharmacology 2016; 41:261-274

Correspondence:

Nenad Jaksic, MPsych

Department of Psychiatry, University Hospital Centre Zagreb

Kispaticeva 12, 10000 Zagreb, Croatia

E-mail:nenad_jaksic@yahoo.com 